\title{
Mn-Mediated $\alpha$-Radical Addition of Carbonyls to Olefins: Systematic Study, Scope, and Electrocatalysis
}

\author{
Sylvain Charvet $^{1}$, Maurice Médebielle ${ }^{1}$, Julien C. Vantourout ${ }^{1 *}$ \\ 1Univ Lyon, Université Lyon 1, CNRS, INSA, CPE-Lyon, ICBMS, UMR 5246, 1 rue Victor Grignard, 69622, Villeurbanne, \\ France. \\ Dedicated to the memory of Professor Gérard Cahiez for his pioneering work in manganese catalysis.
}

\begin{abstract}
A systematic study of the manganese-mediated $\alpha$-radical addition of carbonyl groups to olefins is presented. After an in-depth investigation of the parameters that govern the reaction, a first round of optimization allowed the development of a unified stoichiometric set of conditions which was subsequently assessed during the exploration of the scope. Due to observed limitations, the knowledge accumulated during the initial study was reengaged to quickly optimize promising substrates that were so far inaccessible under previously reported conditions. Altogether these results led to the creation of a predictive model based on the pKa of the carbonyl compound and both the substitution and geometry of the alkene coupling partner. Finally, a departure from the use of stoichiometric manganese was enabled through the development of a robust and practical electrocatalytic version of the reaction.
\end{abstract}

\section{INTRODUCTION}

One of the central challenges of our century is the development of sustainable chemical processes. ${ }^{1}$ Following this concept, the use of first row transition metals has become essential in catalysis. ${ }^{2}$ Manganese is abundant, inexpensive, non-toxic, and participates in myriad of transformations due to the wide range of oxidation states it can adopt (from 0 to $\left.+7,[\mathrm{Ar}] 3 \mathrm{~d}^{5} 4 \mathrm{~s}^{2}\right){ }^{3}$ In the framework of a new research programm dedicated to manganese catalysis, we are particularly interested in the systematic study of reactions previously neglected due to low practicality and lack of mechanistic understanding.

For our first study, we selected the field of $\alpha$-alkylation of carbonyls as it is a central and well-established transformation in organic synthesis that could still benefit from improvement (Figure 1).4 Indeed, the coupling of enolates with nucleofuge-containing molecules under basic conditions is extensively employed, but its low atom-economy makes it often industrially impracticable. ${ }^{5}$ Similarly, modern procedures employing a combination of a metal-based catalyst with directing amines have allowed the use of alkenes as coupling partners, which circumvent any waste generation. ${ }^{6}$ However, the expensive catalysts and/or reagents employed in these protocols make them difficult to implement on scale. Despite the current limitations associated with the Mn-mediated carbonyl $\alpha$-radical addition to olefins (vide infra), we identified this transformation as a full atom-economy alternative to existing enolates and metal-based systems. Therefore, we decided to systematically investigate the parameters that govern this reaction to assemble a general and robust set of conditions that would supplant existing procedures.
Figure 1. Introduction to $\alpha$-alkylation of carbonyls.

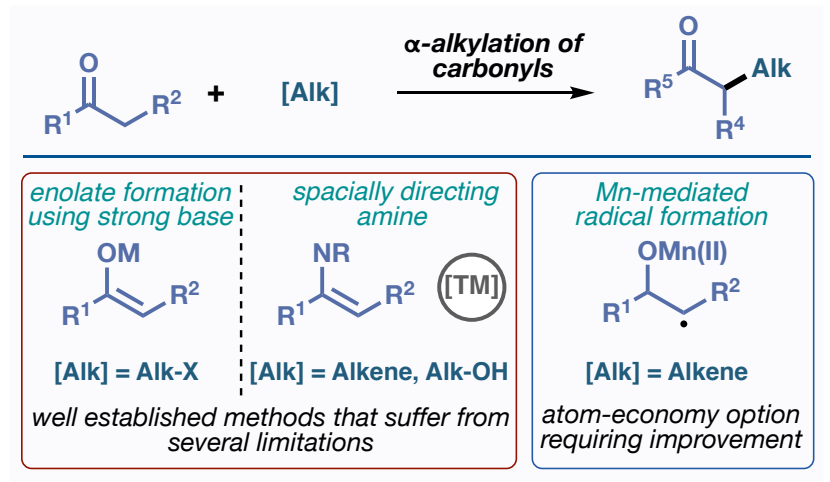

\section{STATE OF THE ART}

Since the seminal 1968 back-to-back publications of Finkbeiner and Heiba, Mn(III) has emerged as an ideal catalyst to promote various oxidative free-radical reactions. ${ }^{7,8}$ In these pioneering reports, a non-activated olefin reacts with solvent quantities of $\mathrm{AcOH}$ in the presence of stoichiometric amount of $\mathrm{Mn}(\mathrm{OAc})_{3}$ and $\mathrm{KOAc}$ at reflux to afford the corresponding lactone (Scheme 1A.1). Two years later, the group of Nikishin demonstrated that a large excess of carbonyl compound (20 equivalents) was also able to react with alkenes in an intermolecular fashion to deliver the $\alpha$-functionalized ketone 2, albeit in low yield (Scheme 1A.2). ${ }^{9}$ Indeed, Mn(III) is able to oxidize carbonyl compounds to generate an $\alpha$-keto free radical, which can subsequently react with an unsaturated substrate to deliver the desired coupled product. ${ }^{10}$ The detailed mechanism of this reaction has been extensively studied and proposed by Peterson and Snider. ${ }^{11,12}$ It subtly depends on the nature of the carbonyl starting material but can generally be 


\section{Scheme 1. Introduction. (A) State of the Art, and (B) Core of this study.}

A. State of the Art

1. First back-to-back reports, Finkbeiner and Heiba (1968)

$$
\begin{aligned}
& \mathrm{KOAC}+\mathrm{C}_{6} \mathrm{H}_{13} \underset{\mathrm{AcOH}, \text { reflux }}{\stackrel{\mathrm{Mn}(\mathrm{OAc})_{3}}{\longrightarrow}} \mathrm{O} \\
& \text { 1, } 74 \%
\end{aligned}
$$

2. First intermolecular report, Nikishin (1970)

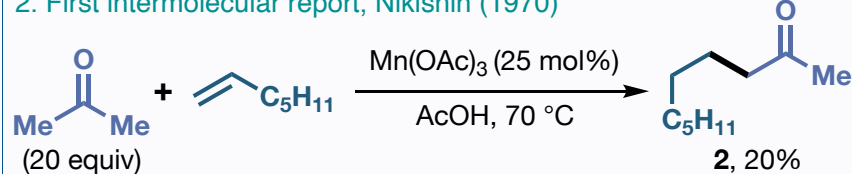

3. Proposed mechanism, Peterson and Snider (1985 and 2009)

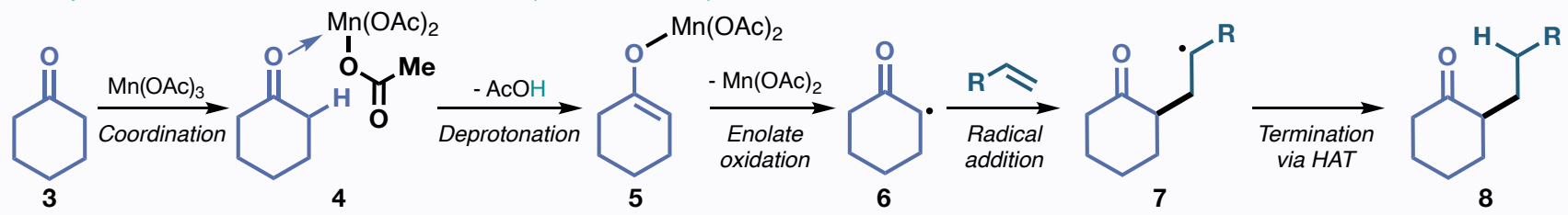

4. Intermolecular stoichiometric approaches General reaction scheme

$$
\begin{aligned}
& \text { - ubiquitous } \mathrm{SM} \text { - applications in synthesis - manganese } \\
& \text { - AcOH as solvent - large excess of ketone - high temperature } \\
& \text { - limited understanding of reaction parameters }
\end{aligned}
$$

Selected applications<smiles>CC(=O)CCCCCCOC(C)=O</smiles>

Queen bee pheromone<smiles>CC(=O)CCCC(C)(C)c1cc(C)ccc1OC(C)=O</smiles>

Himasecolone, 9
5. Intermolecular catalytic approaches

Selected example of oxidative conditions

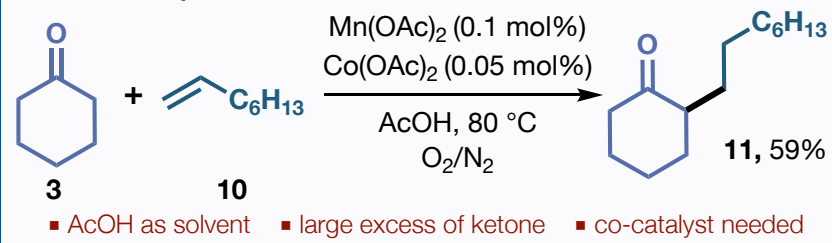

Selected example of electrochemical conditions

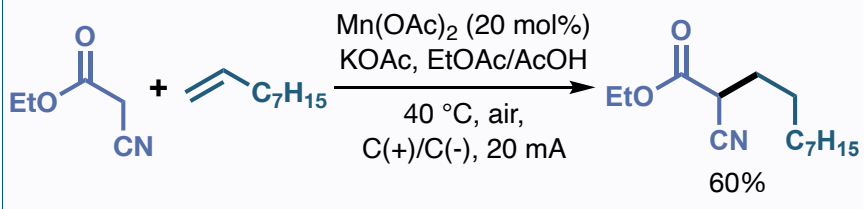

- divided cell - no general set of conditions - use of excess $\mathrm{AcOH}$

B. This Work<smiles>[R]C=C([R])[R]</smiles>

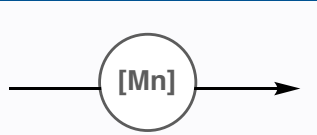<smiles>[R]C([R])C([R])C([R])C(=O)O</smiles>

Stoichiometric Protocol
carbonyl (3 equiv)
$\mathrm{Mn}(\mathrm{OAc})_{3}$ (1.5 equiv)
EtOH as solvent
- good understanding of reaction parameters - EtOH as solvent
- general set of conditions - good FG totelerance

summarized as depicted in Scheme 1A.3. It begins with the coordination of carbonyl 3 onto the $\mathrm{Mn}(\mathrm{OAc})_{3}$ catalyst to form complex 4 , followed by loss of the $\alpha$-proton assisted by one of the acetate groups to generate enolate 5 . The latter is oxidized by $\mathrm{Mn}$ (III) to give the free-radical intermediate 6 that subsequently reacts with the olefin, forging the C$\mathrm{C}$ bond and affording the more stable radical species 7 . This sequence may also be concerted if the enolate oxidation step is sluggish. ${ }^{12}$ Finally, a termination step via hydrogen atom transfer (HAT) allows the formation of desired product 8.

The reaction tolerates a wide range of ubiquitous carbonyl compounds including ketones, esters, keto-esters, diesters, aldehydes, and carboxylic acids. ${ }^{10}$ In addition, the possibility for the carbonyl moieties to react with non-activated olefins using earth abundant manganese renders this transformation highly attractive and broadly applicable, especially in the context of natural product synthesis (Scheme 1A.4).13

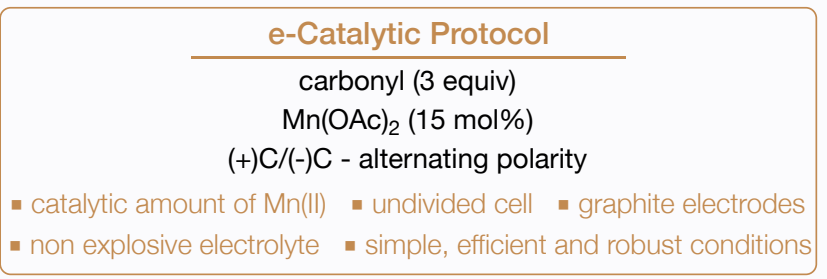

While the Snider group amongst others reported several intramolecular polycyclization cascades, ${ }^{14}$ the Mamdapur group applied the (first?) intermolecular version of the Mnmediated $\alpha$-radical addition of carbonyl groups to olefins as a key step for their synthesis of Himasecolone 9, a phenolic sesquiterpenoid. ${ }^{15}$ Despite all the advantages it offers, the intermolecular version of the reaction still suffers from major limitations such as: (1) the absence of a general set of conditions; (2) the need for a large excess of carbonyl starting material to be employed (usually more than 10 equivalents); (3) the use of acetic acid as the solvent which lowers the functional group tolerance and (4) the lack of understanding with regards to some reaction parameters including temperature, concentration, atmosphere and more importantly the nature of the alkene coupling partner (Scheme 1A.4). These limitations hamper the widespread use of this powerful transformation. Another significant drawback that reduces the broad application of this reaction is the 
(over)stoichiometric amount of $\mathrm{Mn}(\mathrm{OAc})_{3}$ catalyst often required to afford satisfactory yields. ${ }^{10}$ Such excess of manganese catalyst leads to tedious workup as exemplified in several studies. ${ }^{14}$ To overcome this issue, several groups have attempted to run the reaction under oxidative conditions to regenerate $\mathrm{Mn}$ (III) from $\mathrm{Mn}(\mathrm{II}) \cdot{ }^{10,16}$ As a selected example, the Ishii group reported the coupling between cyclohexanone $\mathbf{3}$ and octene $\mathbf{1 0}$ to afford desired product $\mathbf{1 1}$ in 59\% yield (Scheme 1A.5). ${ }^{17}$ This set of conditions only requires $0.1 \mathrm{~mol} \%$ of $\mathrm{Mn}(\mathrm{OAc})_{2}$ catalyst and $0.05 \mathrm{~mol} \%$ of $\mathrm{Co}(\mathrm{OAc})_{2}$ co-catalyst to be employed under a mixed atmosphere of oxygen and nitrogen. However, the large excess of ketone starting material and the use of $\mathrm{AcOH}$ as solvent remain two major limitations which reduce the applicability of the reaction. As an alternative to chemical oxidative conditions, it was demonstrated that $\mathrm{Mn}$ (II) could be oxidized to Mn(III) under electrochemical conditions (Scheme 1A.5). ${ }^{18}$ In these studies, the products are obtained in good yield using low $\mathrm{Mn}(\mathrm{II})$ catalyst loadings (down to $10 \mathrm{~mol} \%$ ). Nevertheless, the use of solvent quantities of $\mathrm{AcOH}$, the necessity to run the reaction in a divided cell, and the absence of a general procedure reduce the synthetic value of this catalytic approach.

The aforementioned limitations have certainly lowered the uptake of the Mn-mediated $\alpha$-radical addition of carbonyl groups to olefins, ${ }^{10 \mathrm{~h}}$ and although this reaction has been exemplified multiple times in the literature it has only been sporadically studied. ${ }^{19}$ We recognized that if rendered practical, such a reaction could undoubtedly impact the field of carbonyl $\alpha$-functionalization. Therefore, we decided to: (1) investigate the parameters that govern this transformation; (2) assemble a general set of stoichiometric reaction conditions; (3) evaluate the scope and its limitations; (4) reengage the knowledge accumulated during the initial study to quickly optimize low yielding substrates and (5) depart from the use of stoichiometric manganese with the development of a general electrocatalytic version of the reaction (Scheme 1B).

\section{RESULTS AND DISCUSSIONS}

\subsection{Systematic study of the reaction parameters}

We began our investigation by studying the parameters that govern the $\mathrm{Mn}$-mediated $\alpha$-radical addition of carbonyls to olefins between cyclohexanone $\mathbf{3}$ and 1-hexadecene $\mathbf{1 2}$ (Scheme 2A). As most of the existing intermolecular processes suffer from the requirement for a large excess of carbonyl compound to be used under oxidative conditions, the excess of ketone $\mathbf{3}$ was limited to three equivalents and the reaction was run under argon. Based on previously reported conditions, $\mathrm{Mn}(\mathrm{OAc})_{3}$ was selected as the stoichiometric catalyst source and the reaction was conducted at 70 ${ }^{\circ} \mathrm{C}$. Inspired by the elegant Mn(III)-catalyzed intramolecular cyclization study disclosed by the Snider group, where the authors described the impact of the solvent on the outcome of the transformation, we initially studied this parameter. ${ }^{20}$ To our surprise, $\mathrm{AcOH}$, which is the prefered solvent for the majority of previously reported conditions, only afforded $14 \%$ of desired product 13 (Scheme 2A.1). This is potentially due to the limited amount of ketone (3 equivalents) used in the reaction, which cannot compete with the competitive lactone formation reported by Finkbeiner and Heiba (Scheme 1A.1). DMA, DME, DMF, MeCN, DCE, and
HFIP were also tested but only delivered moderate yields (22-46\%, Scheme 2A.1). This trend can be rationalized by the reduced ability of these solvents to facilitate the final HAT process as the $\mathrm{H}$-atom source, constraining the ketone starting material or the desired product to serve this role. The subsequent radicals can then result in the formation of unwanted by-products (See SI for details). Out of all the solvents that were screened, EtOH conferred the best result ( $74 \%$ yield) while toluene provided a moderate yield of $58 \%$ (Scheme 2A.1). In each case, the corresponding stabilized $\alpha$-hydroxy or benzylic radical afforded by the HAT termination step can explain why these solvents offered an improved outcome. The remarkably enhanced conversion observed in EtOH can also be supported by several studies which previously highlighted its ability to enhance the reactivity of manganese-based processes. ${ }^{21}$ Screening of commercially available catalyst sources was then attempted using EtOH as the solvent (Scheme 2A.2). Unfortunately, $\mathrm{Mn}(\mathrm{dpm})_{3}$ and $\mathrm{Mn}(\mathrm{acac})_{3}$ resulted in none and $14 \%$ conversion to product 13, respectively. The steric hindrance engendered by dpm or acac ligands surrounding the metalcenter obstructs the formation of coordinated intermediate 4, which impedes product formation. In addition, such ligands could lead to the formation of undesired $\alpha$-functionalized by-products. Non-commercially available $\mathrm{Mn}(\mathrm{pic})_{3}$ catalyst was also tried under the reaction conditions but did not provide satisfactory yield compared to $\mathrm{Mn}(\mathrm{OAc})_{3}$ (See SI for details). Unsurprisingly, the use of $\mathrm{Mn}(\mathrm{OAc})_{2}$ did not afford any product as oxidation to Mn(III) is impossible under an argon atmosphere. The influence of temperature on the reaction was also investigated (Scheme 2A.3). Temperatures lower than $60{ }^{\circ} \mathrm{C}$ considerably diminished the yield as it decreased the solubility of the manganese catalyst, while temperatures higher than $70{ }^{\circ} \mathrm{C}$ significantly increased by-product formation. The impact of the amount of manganese was then studied (Scheme 2A.4). While increasing the number of equivalents from 1 to 1.5 improved the yield of compound 13 from $70 \%$ to $74 \%$, lowering the loading from 1 to 0.5 equivalents resulted in a decreased yield of $51 \%$. This result is in accordance with the proposed mechanism where $\mathrm{Mn}(\mathrm{III})$ is reduced to $\mathrm{Mn}$ (II) to generate keto-radical 6. Under inert conditions, Mn(II) cannot be reoxidized and a (super)stoichiometric amount of manganese needs to be employed. Of note, using a large excess of manganese catalyst (e.g., 3 equivalents) resulted in low conversion to the desired product (44\%), possibly due to precipitation of the catalyst. Several additives were screened and their impact on the reaction efficiency was studied (Scheme 2A.5). Doping the reaction with acidic additives such as $\mathrm{AcOH}, \mathrm{PivOH}$ and $\mathrm{B}(\mathrm{OH})_{3}$ resulted in unexpectedly lower conversions. Unintuitively, adding external bases including KOAc, Et ${ }_{3} \mathrm{~N}$, DIPEA, imidazole, NaOEt or ${ }^{t} \mathrm{BuOK}$ to facilitate the deprotonation step did not increase the yield of the reaction, and instead considerably hampered conversion. We next turned our attention to the atmosphere under which the coupling reaction was being conducted. Running the reaction under argon provided $70 \%$ of desired product 13 while an atmosphere of oxygen only afforded $44 \%$ (Scheme 2A.6). A careful analysis of the by-product distribution allowed us to explain the drastic differences observed between an inert and oxidizing environment (See SI for details). Indeed, under air or oxygen the 
Scheme 2. Development of a unified stoichiometric set of conditions. (A) Study of the influence of key parameters, and (B) Optimized set of reaction conditions. Reactions run on $0.25 \mathrm{mmol}$ scale. A1: cyclohexanone ( 3 equiv), hexadecene ( 1 equiv), $\mathrm{Mn}(\mathrm{OAc})_{3}$ (1.5 equiv), solvent $(0.75 \mathrm{M}), 70^{\circ} \mathrm{C}, \mathrm{Ar}, 16 \mathrm{~h}$.; A2: cyclohexanone (3 equiv), hexadecene (1 equiv), catalyst (1 equiv), EtOH ( 0.75 $\mathrm{M}), 70^{\circ} \mathrm{C}, \mathrm{Ar}, 16 \mathrm{~h}$.; A3: cyclohexanone (3 equiv), hexadecene (1 equiv), $\mathrm{Mn}(\mathrm{OAc})$ s (1 equiv), EtOH (0.75 M), temperature, Ar, 16 h.; A4: cyclohexanone (3 equiv), hexadecene (1 equiv), $\mathrm{Mn}(\mathrm{OAc}) 3$ (equivalents), EtOH $(0.75 \mathrm{M}), 70^{\circ} \mathrm{C}, \mathrm{Ar}, 16$ h.; $\mathrm{A5}$ : cyclohexanone (3 equiv), hexadecane ( 1 equiv), $\mathrm{Mn}(\mathrm{OAc})_{3}$ ( 1 equiv), EtOH ( $0.75 \mathrm{M}$ ), additive ( 3 or 5 equiv, see $\mathrm{SI}$ for details), $70^{\circ} \mathrm{C}, \mathrm{Ar}, 16 \mathrm{~h}$; $\mathrm{A6}$ : cyclohexanone ( 3 equiv), hexadecene (1 equiv), $\mathrm{Mn}(\mathrm{OAc})_{3}\left(1\right.$ equiv), $\mathrm{EtOH}(0.75 \mathrm{M}), 70^{\circ} \mathrm{C}$, atmosphere, $16 \mathrm{~h}$.; A7: cyclohexanone (equivalents), hexadecene (1 equiv), $\mathrm{Mn}(\mathrm{OAc})_{3}$ ( 1 equiv), EtOH $(0.75 \mathrm{M}), 70^{\circ} \mathrm{C}, \mathrm{Ar}, 16 \mathrm{~h}$.; A8: cyclohexanone (3 equiv), hexadecene (1 equiv), $\mathrm{Mn}(\mathrm{OAc})$ s $_{3}(1 \mathrm{equiv})$, EtOH (concentration), $70{ }^{\circ} \mathrm{C}, \mathrm{Ar}, 16 \mathrm{~h}$. Yields refer to GCMS yields using 1,3,5-trimethoxybenzene as an internal standard. Isolated yields are shown in brackets.

\section{A. Influence of the reaction parameters}

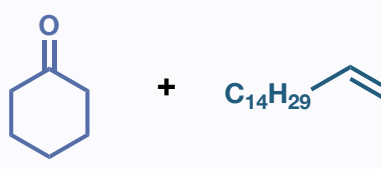

12

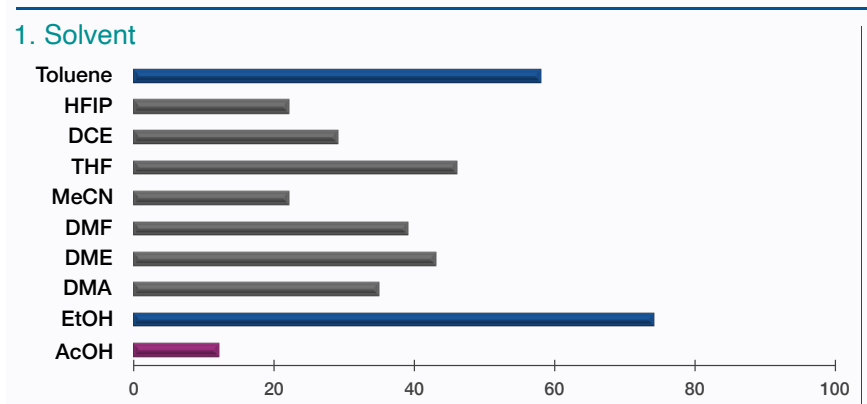

2. Catalyst

$\mathrm{Mn}(\mathrm{OAc})_{2}$

$\mathrm{Mn}(\mathrm{acac})_{3}$

$\mathrm{Mn}(\mathrm{dpm})_{3}$

$\mathrm{Mn}(\mathrm{OAc})_{3}$

3. Temperature

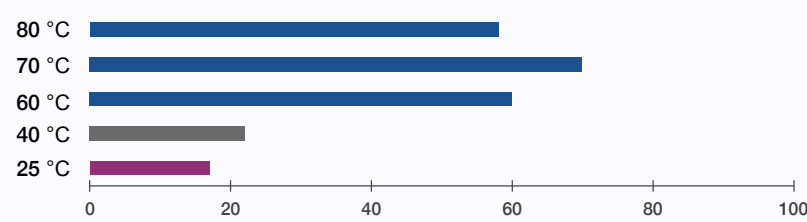

4. Manganese stoichiometry

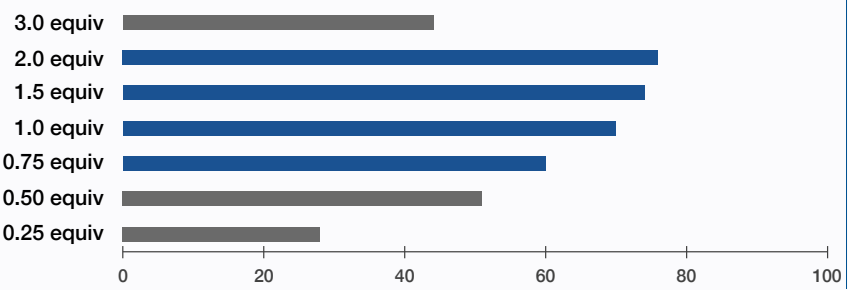

100

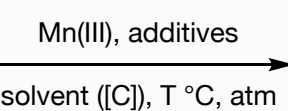

\section{Atmosphere}

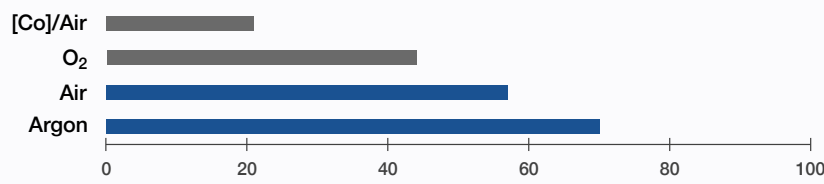

7. Ketone stoichiometry

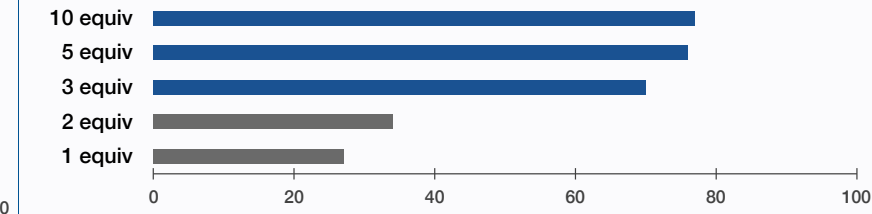

8. Concentration
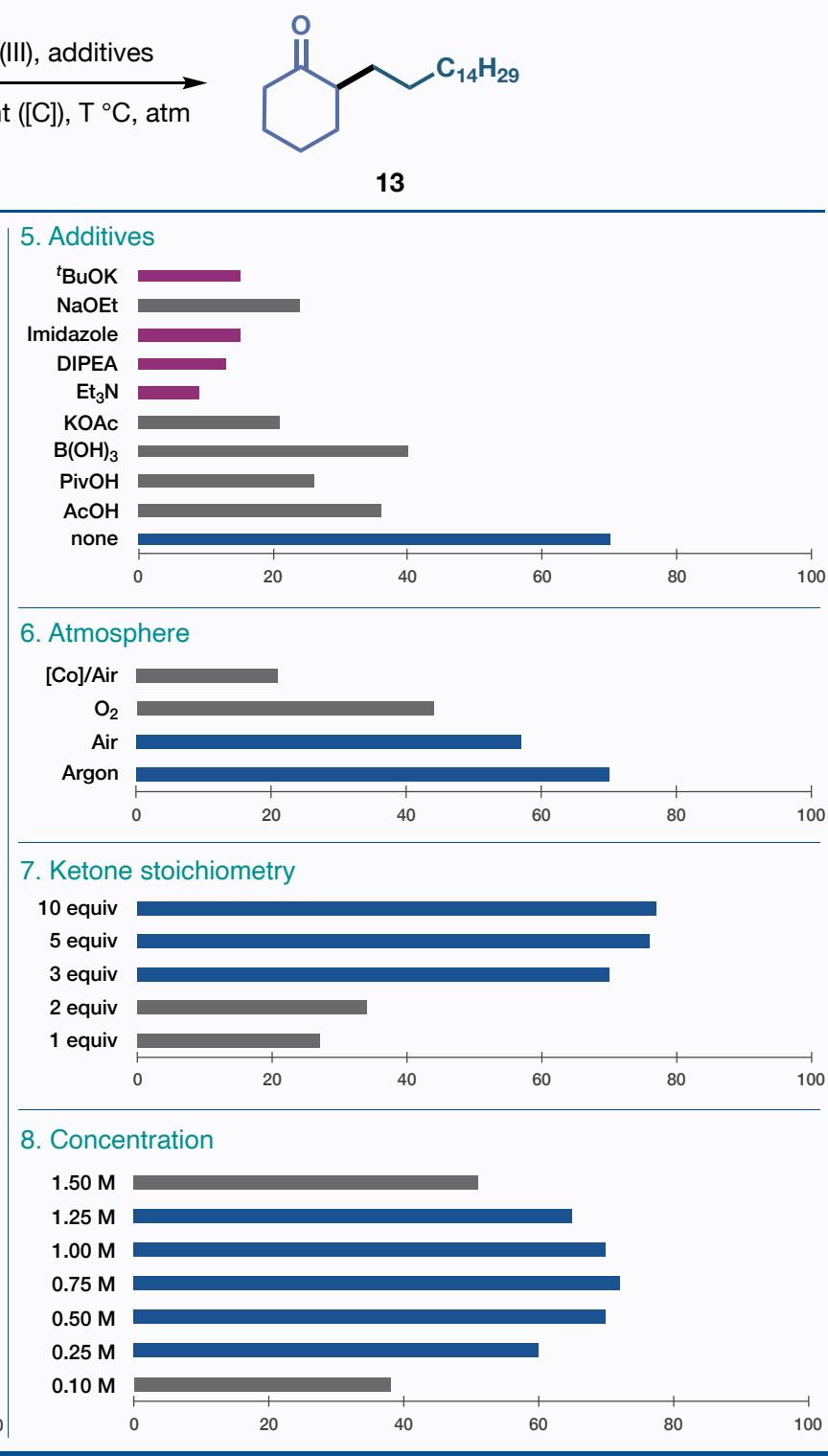

13

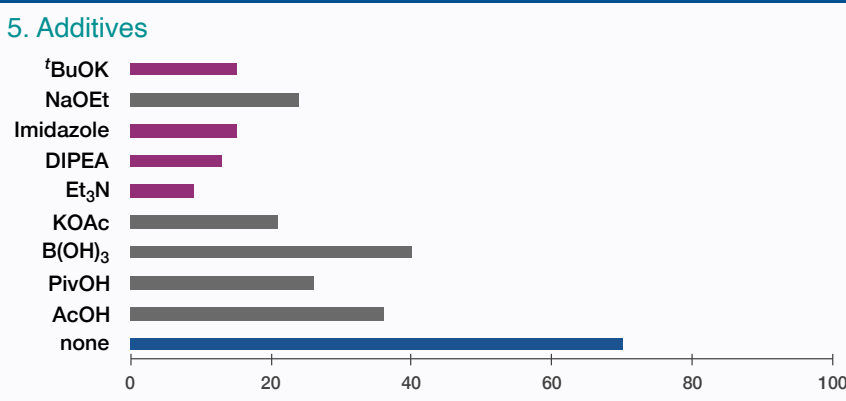

B. Optimized reaction conditions

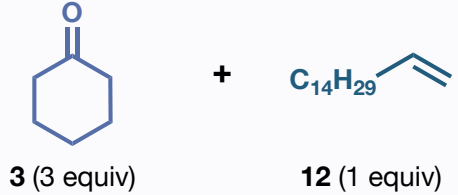

ketone starting material is consumed by undesired processes leading to dimeric and $\alpha$-oxidized species, thus lowering the overall yield of the reaction. Based on the elegant study from the group of Ishii, the impact of using a Co(II) cocatalyst was also reevaluated (vide supra) ${ }^{17}$ Attempts to 
2A.7). The use of a large excess of ketone (5 or 10 equivalents) delivered high yields, matching with previously reported results from the literature. ${ }^{10}$ Finally, as both solubility of the manganese catalyst and overall concentration of the ketone starting material appeared to greatly impact the yield of the reaction, we hypothesized that the concentration should also play an important role in the outcome of the transformation (Scheme 2A.8). Moving from a concentration of $0.5 \mathrm{M}$ to $0.1 \mathrm{M}$ significantly decreased the yield from $70 \%$ to $38 \%$. Similarly, the yield of the reaction was markedly lowered when the concentration was too high due to catalyst insolubility and lower stirring efficiency.

\subsection{Optimized stoichiometric set of reaction conditions}

Using the knowledge gained throughout this in-depth study a simple and general Mn-mediated $\alpha$-radical addition of carbonyls to olefins was developed (See SI for details). Running the reaction with a slight excess of $\mathrm{Mn}(\mathrm{OAc})_{3}$ in EtOH at suitable temperature $\left(70^{\circ} \mathrm{C}\right)$ and concentration $(0.75 \mathrm{M})$ under an atmosphere of argon delivered desired product $\mathbf{1 3}$ in $67 \%$ isolated yield with only 3 equivalents of carbonyl starting material (Scheme 2B).

\subsection{Scope of the reaction}

With the optimized conditions in hand, we first started to assess the carbonyl scope (Scheme 3A). Ketones such as cyclopentanone, acetone and indanone delivered compounds 14, 15 and 16 in 70\%, 59\% and 40\% isolated yields, respectively. Noteworthy, the conversion for compounds $\mathbf{1 5}$ and 16 (83\% and $97 \%$, respectively) was much higher than the isolated yield due to challenging purification. $\alpha$-Tetralone, which was known to be unreactive under previously reported conditions, afforded compound $\mathbf{1 7}$ in 17\% yield. Boc-protected piperidin-4-one afforded desired product 18 in $63 \%$ isolated yield. Strikingly, this compound was only obtained in trace amount following the original literature conditions which highlights the importance of using EtOH instead of $\mathrm{AcOH}$ to improve functional group tolerance. $\mathrm{Ni}$ troacetate gave cyclized product $\mathbf{1 9}$ in a moderate isolated yield of 33\%. Other carbonyls including diester, keto-ester and cyanoacetate proved compatible under the reaction conditions with compounds 20, 21 and 22 obtained in good yields (63-74\%). Unfortunately, due to higher $\alpha-\mathrm{C}-\mathrm{H}$ pKa values, amides and esters did not react under the reaction conditions (compounds $\mathbf{3 1}$ and 32, Scheme 3C). Similarly, compound 33 issued from the coupling between methyl isopropyl ketone (MIPK) and 1-hexadecene $\mathbf{1 2}$ was only detected in negligeable amounts (traces in GCMS).

Regarding the alkene scope, stabilized disubstituted olefins such as prop-1-en-2-yl acetate when reacting with cyclohexanone $\mathbf{3}$ delivered product $\mathbf{2 6}$ in $61 \%$ isolated yield. Alkynes were also successfully coupled under the reaction conditions with the corresponding $(E)$-alkene $\mathbf{2 8}$ obtained in $43 \%$ yield. Functionalization of valuable alkenes such as camphene and $(+)-\beta$-citronellene afforded different outcomes with compounds 29 obtained in $66 \%$ while only trace amount of compound $\mathbf{3 0}$ was detected. In addition, cyclohexene when coupled with indanone delivered compound 27 , in $16 \%$ isolated yield highlighting that 1,2-disubstituted non-stabilized olefins are challenging compounds to functionalize. This trend was further confirmed when 1- methylcyclohex-1-ene, (E)-non-4-ene, or (Z)-non-4-ene were used as alkene coupling partners with no desired or trace product formation observed.

Regarding functional group tolerance, the optimized reaction conditions proved highly efficient. Indeed, ester (20-22 and 26), cyano (22), nitro (19), free (24) or TBS (23) protected alcohols, and acetyl groups (26) were all tolerated under the reaction conditions and afforded the desired products from moderate to good yields ( $27 \%$ to $74 \%)$. Notably, halogen moieties were also stable under the reaction conditions with bromine containing compound $\mathbf{2 5}$ obtained in $56 \%$. To further assess the functional group tolerance, a robustness test was performed by adding one equivalent of an additive bearing a specific reactive handle (Scheme 3D). ${ }^{22}$ While phenol, amide and carboxylic acid moieties did not impact the outcome of the reaction, amine- and nitrobased compounds hampered both conversion and yield. Interestingly, pyridine lowered the conversion $73 \%$ instead of $92 \%$ ) but afforded a serviceable yield (53\% instead of $74 \%)$.

Overall, the optimized set of reaction conditions delivered a broad scope but some unexpected and contrasting results highlighted the difficulty to identify a truly general set of conditions, especially with respect to the alkene coupling partners. To equally compare our newly developed conditions to the previously reported ones, we decided to run a control where 10 equivalents of carbonyl was used in $\mathrm{AcOH}$ in the presence of 2.0 equivalents of $\mathrm{Mn}(\mathrm{OAc})_{3}$ at $70{ }^{\circ} \mathrm{C}$. Strikingly, except for nitroacetate, our reaction conditions outperformed the control experiments. More importantly, for compounds 17, 27, 30, 33 and 36 our conditions always afforded product, while previously reported ones were ineffective. This observation motivated us to try to understand the reaction further to optimize for those low yielding substrates.

\subsection{Rapid optimization of low yielding substrates}

We envisioned that we could re-apply the knowledge accumulated during our systematic study to identify key parameters that should impact the outcome of the reaction. If successful, this approach would allow the practitioner to quickly identify optimal reaction conditions to give at least some product under the general stoichiometric set of conditions for challenging substrates.

Throughout our initial investigation of the Mn-mediated $\alpha$ radical addition of carbonyls to olefins, parameters such as solvent, temperature, manganese loading, and concentration were found to dramatically impact the reaction outcome (Scheme 2). Due to its importance in previously reported conditions, $\mathrm{AcOH}$ was also a variable that needed to be considered. ${ }^{10}$ With those parameters in mind, eight sets of conditions were designed and assessed on eight substrates containing seven ketones and two alkenes. Depending on the substrates and the conditions used, huge reactivity differences were observed matching with the observed difficulty to develop a truly general protocol (vide supra). As an example, cyanoester afforded high conversions to desired product $\mathbf{2 2}$ under all tested conditions even at room temperature. This extremely high reactivity can explain why it is one of the most frequently used substrates in 
Scheme 3. Scope of the reaction. (A) Carbonyls, (B) Alkenes, (C) Limitations, and (D) Robustness test. Yields refer to GCMS yields using 1,3,5-trimethoxybenzene as an internal standard. Isolated yields are shown in brackets.

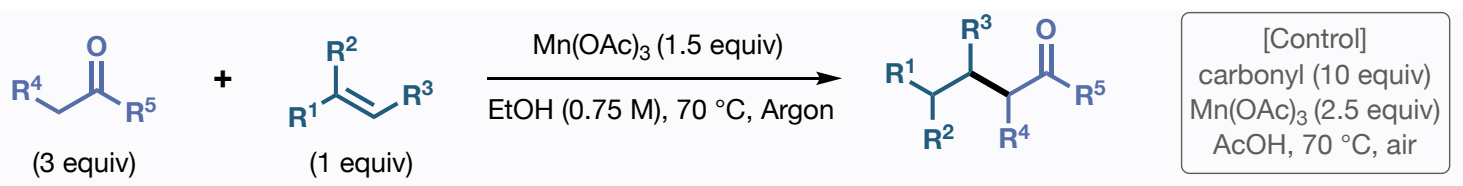

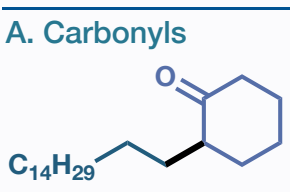

$13,74 \%(67 \%)$ [Control]: $63 \%$<smiles>CCCCCCCCCC1CN(C(=O)OCc2ccccc2)CCC1=O</smiles>

$18,71 \%(63 \%)$

[Control]: traces

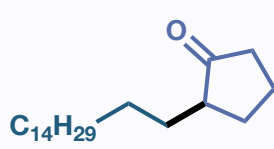

\section{$14,83 \%(70 \%)$} [Control]: 51\%

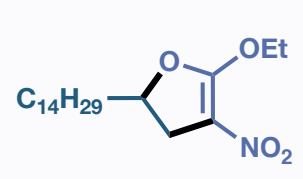

$19,45 \%(33 \%)$ [Control]: 80\%

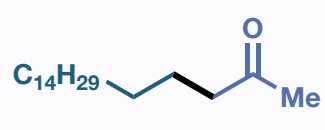

$15,{ }^{\text {a }} 83 \%(59 \%)$ [Control]: 7\%

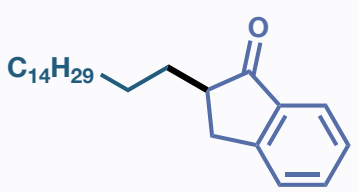

$16,97 \%(40 \%)$ [Control]: $12 \%$<smiles>CCCCCCCCC1CCc2ccccc2C1=O</smiles>

$17,25 \%$ (17\%)

[Control]: n.r.

B. Alkenes

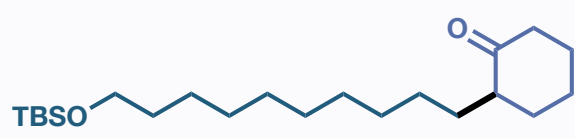

23, $90 \%(50 \%)$ [Control]: $50 \%$

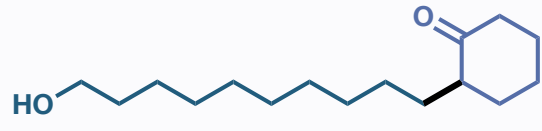

24, $58 \%(46 \%)$

[Control]: 15\%<smiles>CCCCCCCCCCCCCCCCCC(C(=O)OC)C(=O)OC</smiles>

$21,81 \%(74 \%)$

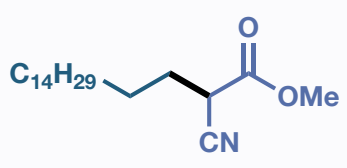

22, $96 \%(72 \%)$ [Control]: $85 \%$
20, $95 \%$ (63\%) [Control]: $45 \%$<smiles>O=C1CCCCC1CCCCCCCCBr</smiles>

$25,60 \%(56 \%)$

[Control]: $25 \%$<smiles>CC(=O)OC(C)CC1CCCCC1=O</smiles>

26, $70 \%$ (61\%) (1:1 dr) [Control]: $21 \%$

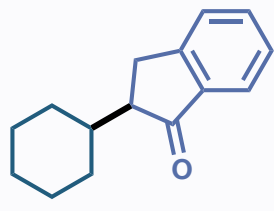

27, (16\%) [Control]: n.r.

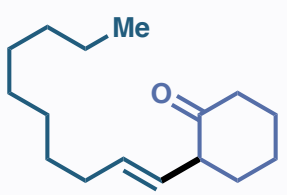

28, (from alkyne) $54 \%$ (43\%) [Control]: traces

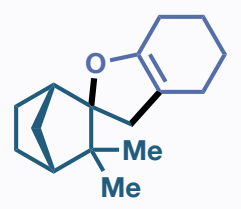

29, 66\% (3:1 dr) [Control]: n.r.

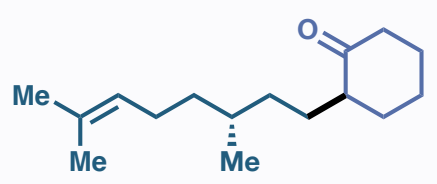

30, traces [Control]: n.r.

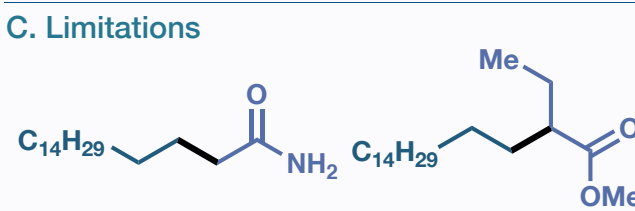

31, n.r. [Control]: n.r.
32, n.r. [Control]: n.r.<smiles>CCCCCCCCCCC(=O)C(C)C</smiles>

33, traces

[Control]: n.r.<smiles>CC1CCCCC1C1CCCCC1=O</smiles>

34, n.r. [Control]: n.r.<smiles>CCCCC(CCCC)C1CCCCC1=O</smiles>

35, (from trans) ; 36 , (from cis) n.r. traces [Control]: n.r. : [Control]: n.r.

\section{Robustness test}<smiles>O=C1CCCCC1</smiles>

3

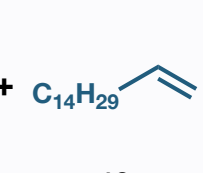

12

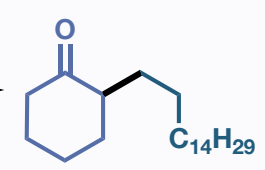

13

\begin{tabular}{rcc} 
& conversion & yield \\
\hline piperidine & 43 & 22 \\
aniline & 17 & $<5$ \\
pyridine & 73 & 53 \\
nitrobenzene & 18 & $<5$
\end{tabular}

\begin{tabular}{rcc} 
& conversion & yield \\
\hline phenol & 93 & 73 \\
benzamide & 87 & 67 \\
AcOH & 90 & 72 \\
none & 92 & 74
\end{tabular}

literature reports. ${ }^{23}$ Conversely, several changes impacted the conversion to product $\mathbf{1 9}$ which results from the coupling between nitroacetate with hexadecene. Running the reaction with more equivalents of manganese (from 1.5 to 2.5 equivalents), higher temperature (from $70{ }^{\circ} \mathrm{C}$ to $90^{\circ} \mathrm{C}$ ), higher concentration (from $0.75 \mathrm{M}$ to $1 \mathrm{M}$ ) or using $\mathrm{AcOH}$ as an additive (5 or 10 equivalents) provided better conversions versus the original conditions. The reactivity of $\alpha$-tetralone, which already delivered reasonable conversion (25\%), was enhanced by simply adding 5 equivalents of $\mathrm{AcOH}$ to afford $56 \%$ of desired product 17 . Similarly, compound 37 was obtained in a moderate yield of $43 \%$ by increasing the amount of manganese from 1.5 to 2.5 equivalents. 
Scheme 4. Broadening the scope of the reaction. (A) Reengaging data from the systematic study, (B) Rapid optimization of initially low yielding compounds, and (C) Predicting reaction outcome. Yields refer to GCMS yields using 1,3,5-trimethoxybenzene as an internal standard. Isolated yields are shown in brackets.

A. Reengaging data from the systematic study

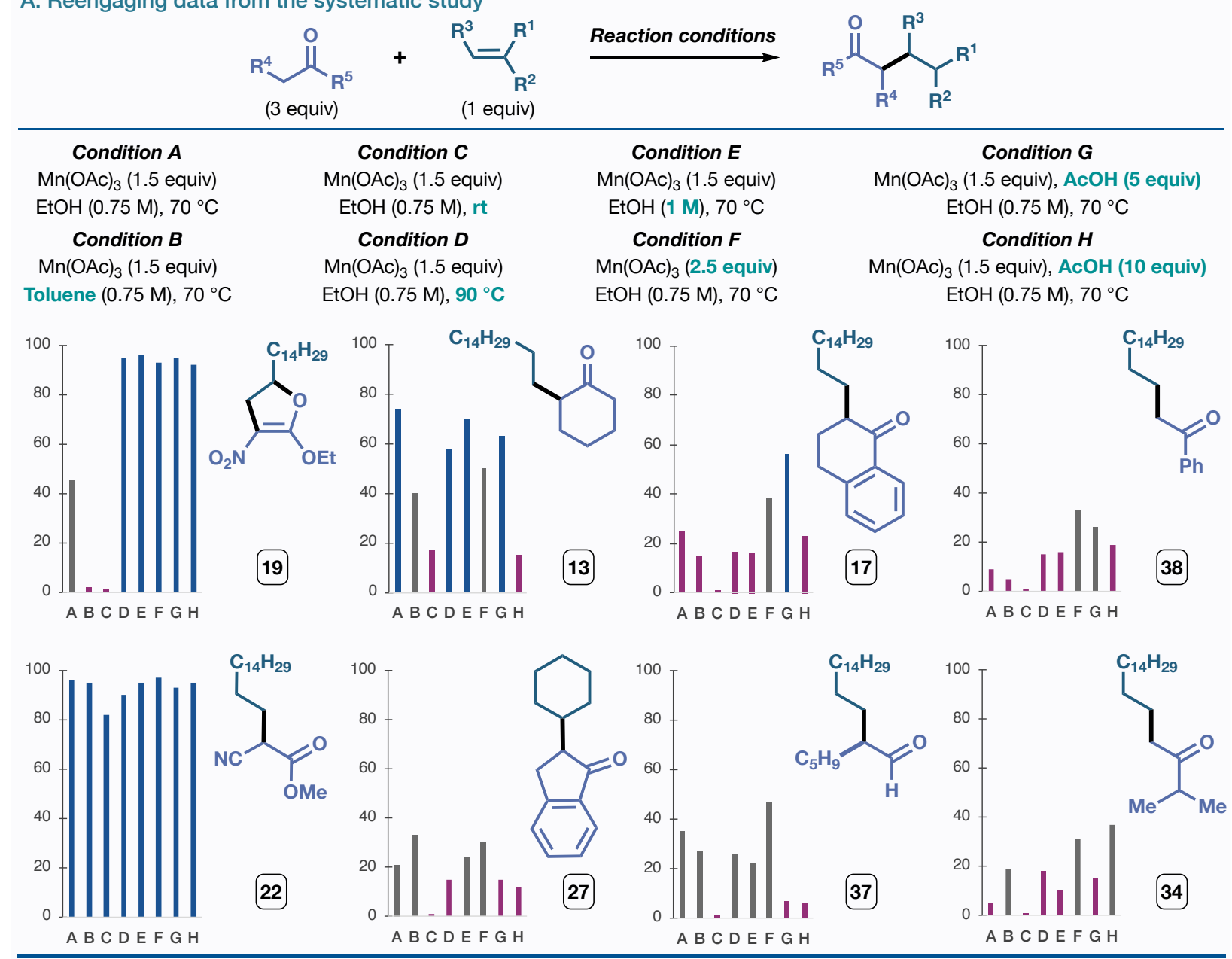

B. Rapid optimization of low yielding compounds

New conditions $\mathrm{Mn}(\mathrm{OAc})_{3}$ (2.5 equiv) AcOH (10 equiv) Toluene $(0.75 \mathrm{M}), 90^{\circ} \mathrm{C}$<smiles>CCCCCCCCC(=O)C(C)C</smiles>

33 , from traces to $(50 \%)$
New conditions $\mathrm{Mn}(\mathrm{OAc})_{3}$ (2.5 equiv) $\mathrm{AcOH}$ (5 equiv) $\mathrm{EtOH}(0.75 \mathrm{M}), 70^{\circ} \mathrm{C}$

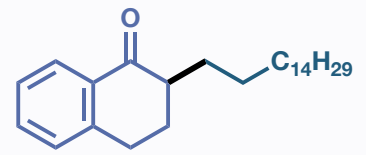

17 , from $(17 \%)$ to $(49 \%)$
New conditions $\mathrm{Mn}(\mathrm{OAc})_{3}$ (2.5 equiv) AcOH (10 equiv) Toluene (1 M), $70{ }^{\circ} \mathrm{C}$

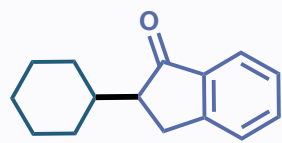

27 , from (16\%) to $(44 \%)$
New conditions $\mathrm{Mn}(\mathrm{OAc})_{3}$ (2.5 equiv)

AcOH (5 equiv) $\mathrm{EtOH}(0.75 \mathrm{M}), 90^{\circ} \mathrm{C}$<smiles>CCCCCCCCCCCCCCCCCCCC</smiles>

19 , from $(33 \%)$ to $(66 \%)$

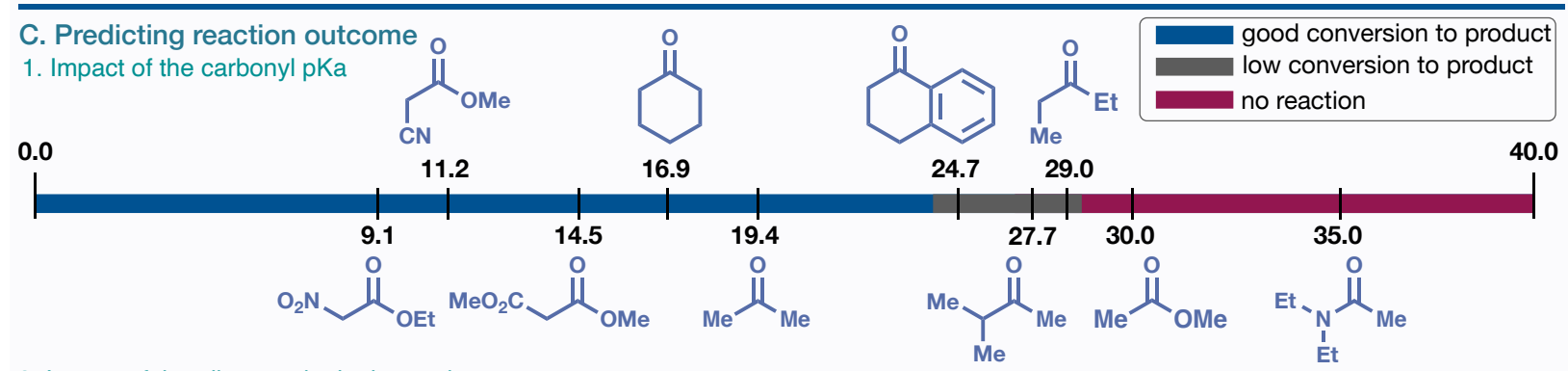

2. Impact of the alkene substitution and geometry

$$
=\gamma^{\mathrm{R}} \quad \equiv-\mathrm{EDG}_{\mathrm{R}}^{\mathrm{R}^{1}}
$$

good conversion to product under standard conditions
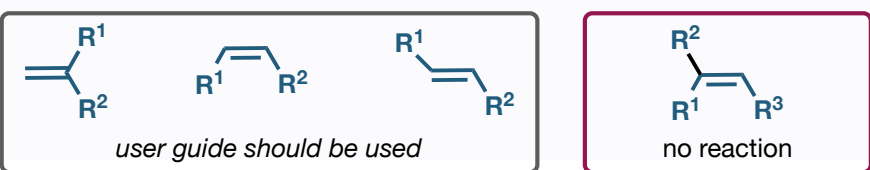
While trying to optimize compounds $\mathbf{2 7}, \mathbf{3 3}$ and $\mathbf{3 8}$ proved more difficult, several conditions still afforded decent conversions $(20-50 \%)$. Therefore, it was envisioned that the combination of all promising set of conditions could significantly increase the yield of initially low conversion reactions. This merged approach was attempted on several substrates, and the results are highlighted in Scheme 4B. Outstandingly, compounds 33, 17, 27 and 19, which were initially only observed in trace amounts or isolated in low yields using the initial set of conditions, were obtained in $50 \%, 49 \%, 44 \%$ and $66 \%$ isolated yield, respectively.

Testing of these simple parameters (manganese loading, temperature, concentration, $\mathrm{AcOH}$ additive), can quickly identify optimized conditions for challenging substrates. However, we thought it would be even better if the practitioner could predict the reaction outcome based on the nature of the carbonyl and the olefin.

\subsection{Predicting reaction outcome}

The systematic optimization, scope evaluation and the subsequent re-optimization of low yielding compounds afforded copious data on reaction outcomes and allowed for a predictive model that relied on (1) the pKa of the carbonyl and (2) the geometry and substitution of the olefin to be assembled (Scheme 4C).

Several studies have highlighted the importance of steric hindrance and pKa depending on the nature of the carbonyl coupling partner. ${ }^{10,24}$ However, no general trends have been reported due to the complexity of the transformation and the myriad of conditions associated to it. Based on our stoichiometric set of conditions, the reaction outcome can be predicted by simply using the pKa of the carbonyl starting material (Scheme 4C.1). Carbonyl compounds with a pKa lower than 24 will provide good yields under the optimized stoichiometric conditions. For carbonyls with pKas between 24 and 29, the approach developed for the low yielding compounds should be applied to obtain satisfactory yields. Compounds with pKas higher than 29 such as esters and amides won't deliver the desired product.

As highlighted by several reviews, the impact of the substitution and geometry of the alkene coupling partner has not been deeply studied..$^{10}$ Indeed, most of the examples reported in the literature focus on the functionalization of terminal non-substituted and cyclic olefins. The evaluation of the reaction scope and the optimization of its limitations allowed us to rationalize outcomes based on the nature of the olefin (Scheme 4C.2). Terminal alkenes and alkynes as well as stabilized disubstituted olefins are well tolerated under the reaction conditions and should afford good yields using the standard stoichiometric protocol. For non-stabilized, cyclic, and cis/trans alkenes the eight conditions designed using the systematic study should deliver moderate yields. When the olefin is too encumbered no desired product should be expected.

\subsection{Development of an electrocatalytic set of conditions}

With the stoichiometric set of conditions, the knowledge accumulated from the systematic study, and the ability to predict the reaction outcome, the practitioner will be able to confidently run the Mn-mediated $\alpha$-radical addition of carbonyls to olefins. However, the need for a stoichiometric amount of $\mathrm{Mn}(\mathrm{OAc})_{3}$ was still a serious limitation from a
Scheme 5. Electrochemical Mn-mediated $\alpha$-radical addition of carbonyls to olefins. (A) e-oxidation of Mn(II) to Mn(III), (B) Optimum [Mn]/[AcOH] ratio, (C) Optimization, and (D) Scope. Reactions were conducted on a 0.6 mmol unless otherwise state. aGCMS yields using 1,3,5-trimethoxybenzene as an internal standard. bIsolated yields are shown in brackets. 'Reactions were conducted on a $1.2 \mathrm{mmol}$ scale in EtOH $(0.5 \mathrm{M})$ at $70^{\circ} \mathrm{C}$. ${ }^{\mathrm{O}}$ Reaction was conducted on a $1.2 \mathrm{mmol}$ scale using 20 equivalents of $\mathrm{AcOH}$ in toluene/EtOH $(1: 1,0.5 \mathrm{M})$ at $90^{\circ} \mathrm{C}$.

\section{A. Validating the e-oxidation of $\mathrm{Mn}$ (II) to $\mathrm{Mn}$ (III)}

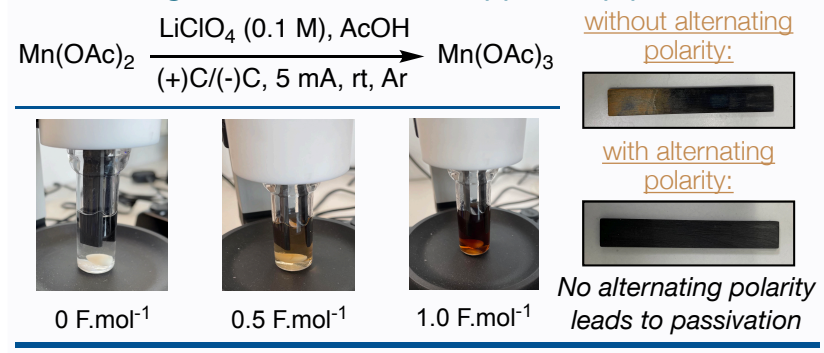

B. Finding the optimum ratio $\mathrm{Mn} / \mathrm{AcOH}$<smiles>CCCCCCCCC(C#N)C(=O)OC</smiles>

\section{Conditions}

methylcyanoacetate (3 equiv) $\mathrm{Mn}(\mathrm{OAc})_{2}(10 \mathrm{~mol} \%), \mathrm{AcOH}$ (X equiv) $\mathrm{LiClO}_{4}(0.1 \mathrm{M}), \mathrm{EtOH}, \mathrm{rt}, \mathrm{Ar}$ $5 \mathrm{~mA},(+) \mathrm{C} /(-) \mathrm{C}, 3.0$ F.mol ${ }^{-1}$ alternating polarity (60s)
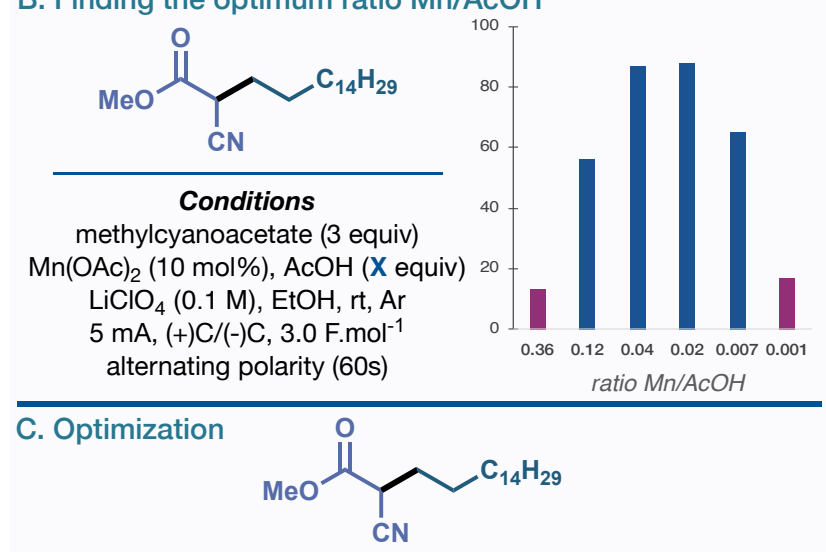

methylcyanoacetate (3 equiv), $\mathrm{Mn}(\mathrm{OAc})_{2}$ (15 mol\%) $\mathrm{AcOH}$ (7.5 equiv), $\mathrm{LiClO}_{4}(0.1 \mathrm{M}), \mathrm{EtOH}(0.25 \mathrm{M}), \mathrm{rt}, \mathrm{Ar}$ $5 \mathrm{~mA},(+) \mathrm{C} /(-) \mathrm{C}, 3.0 \mathrm{~F}^{\mathrm{mol}}{ }^{-1}$. alternating polarity (60s)

\begin{tabular}{cc}
\hline deviation from above conditions & yield \\
\hline none & $>95 \%$ \\
no AcOH & $<5 \%$ \\
10 mol\% Mn(OAc) & 2 \\
no alternating polarity & $88 \%$ \\
$5 \mathrm{~mA}, 1.5 \mathrm{~F} \cdot \mathrm{mol}^{-1}, 5 \mathrm{~h}$ & $15 \%$ \\
$10 \mathrm{~mA}, 3.0 \mathrm{~F}_{\mathrm{mol}}^{-1}, 5 \mathrm{~h}$ & $49 \%$ \\
$\mathrm{LiBF}_{4}$ instead of $\mathrm{LiClO}_{4}$ & $68 \%$ \\
$\mathrm{LiBF}_{4}$ instead of $\mathrm{LiClO}_{4}$ and $0.5 \mathrm{M}$ & $90 \%(77 \%)$ \\
\hline
\end{tabular}

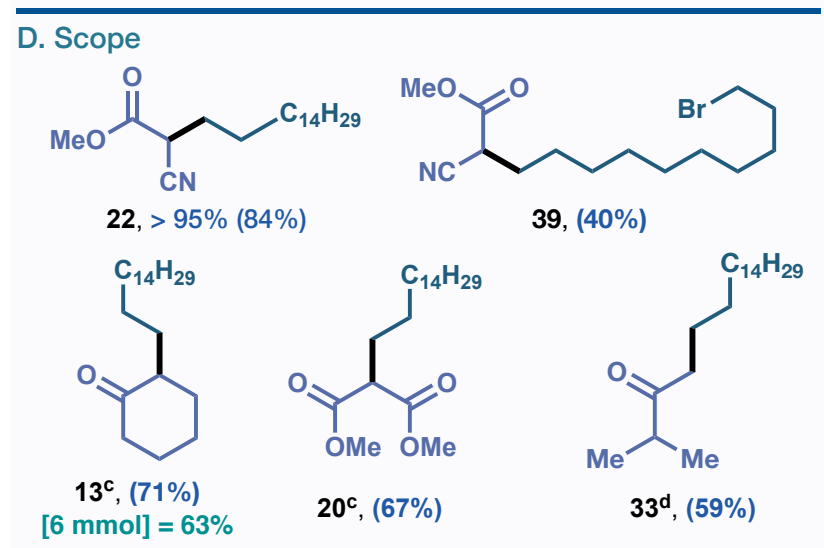


sustainability and scalability standpoint. The development of a catalytic version was therefore sought. As mentioned in the introduction electrochemical alternatives have been attempted for Mn(III)-mediated reactions but have either not proven general, were not deeply investigated, or suffered from limitations such as the requirement for a divided cell and limited substrate scope.14e,18,23b,25 Therefore, the development of a robust electrochemical version of the Mn-mediated carbonyl $\alpha$-radical addition to olefins was undertaken.

The oxidation of Mn(II) to Mn(III) was first studied in an undivided cell equipped with graphite anode and cathode (Scheme 5A). The reaction was conducted using $\mathrm{Mn}(\mathrm{OAc})_{2}$ as the catalyst in $\mathrm{AcOH}$ at room temperature under argon. $\mathrm{AcOH}$ was selected as solvent due to the dual role it would ensure through the course of the catalytic reaction. While proton reduction would occur at the cathode, the subsequently generated acetate would assist the regeneration of $\mathrm{Mn}(\mathrm{OAc})_{3}$ active catalyst at the anode. After $1 \mathrm{~F} \cdot \mathrm{mol}^{-1}$ the formation of $\mathrm{Mn}(\mathrm{OAc})_{3}$ was clearly detected. However, passivation of the electrodes was also observed and could explain why existing methodologies required the use of a cumbersome divided cell setup. Pleasingly, applying simple alternating polarity suppressed this undesirable passivation, allowing for the reaction to be conducted in an undivided cell.

With this proof of concept in hand, the carbonyl starting material was carefully selected. Indeed, cyanoacetate was an ideal coupling partner to start the optimization with as it allowed the reaction to be conducted at room temperature and tolerated the use of AcOH (vide supra, Scheme 4). The excess of carbonyl was maintained at 3 equivalents while the amount of $\mathrm{Mn}(\mathrm{OAc})_{2}$ was fixed at $10 \mathrm{~mol} \%$. Based on our earlier optimization studies, the impact of the $[\mathrm{Mn}] /[\mathrm{AcOH}]$ ratio on the reaction outcome was first investigated (Scheme 5B). As expected, a high $[\mathrm{Mn}] /[\mathrm{AcOH}]$ ratio did not lead to sufficient concentration of active catalyst and afforded the desired product in low yield. Conversely, too much $\mathrm{AcOH}$ in the reaction gave a low $[\mathrm{Mn}] /[\mathrm{AcOH}]$ ratio and reduced the efficiency of the transformation. The optimal $[\mathrm{Mn}] /[\mathrm{AcOH}]$ ratio was obtained using 7.5 equivalents of $\mathrm{AcOH}$ which afforded the desired product 22 in $88 \%$ yield. With this optimized ratio in hand, we turned our attention to the electrochemical reaction conditions (Scheme 5C). To maximize the conversion, $15 \mathrm{~mol} \%$ of $\mathrm{Mn}(\mathrm{OAc})_{2}$ catalyst was used in the presence of 11.3 equivalents of $\mathrm{AcOH}$ to maintain the $[\mathrm{Mn}] /[\mathrm{AcOH}]$ ratio $(0.02)$. Under these conditions, the desired product was obtained in more than $95 \%$ yield. A control experiment without AcOH led to extremely low conversion. In the absence of alternating polarity, compound 22 was only obtained in $15 \%$ yield supporting the detrimental impact of electrode passivation on the reaction outcome. Using $1.5 \mathrm{~F} \cdot \mathrm{mol}^{-1}$ instead of $3.0 \mathrm{~F} \cdot \mathrm{mol}^{-1}$ only delivered $49 \%$ of the desired compound, while using $10 \mathrm{~mA}$ instead of $5 \mathrm{~mA}$ also lowered the yield to $68 \%$. To avoid scalability issues associated with the use of perchlorate-based electrolytes, $\mathrm{LiBF}_{4}$ was used instead of $\mathrm{LiClO}_{4}$ which maintained high conversion to product 22 and good isolated yield (77\%). Finally, aware of the beneficial effect of running the reaction at high concentration, the electrochemical conditions were concentrated up to $0.5 \mathrm{M}$ (instead of 0.25 M) and compound 22 was isolated in $84 \%$.
We then decided to synthesize several molecules to assess the efficiency of the electrochemical protocol (Scheme 5D). Compound 39 bearing a halogen moiety was isolated in $40 \%$ yield. As expected, compounds 13 and 20 which usually require higher temperature to proceed in good yield, did not give satisfactory results at room temperature. Simply heating these reactions to $70{ }^{\circ} \mathrm{C}$ afforded good yields (71\% for 13 and $67 \%$ for 20 ). In addition, the reaction was easily scaled-up to $6 \mathrm{mmol}$ in a single $20 \mathrm{~mL}$ ElectraSyn vial by adjusting the current to $25 \mathrm{~mA}$. Finally, the knowledge gained throughout the study was easily transferable to the electrochemical protocol with compound $\mathbf{3 3}$ obtained in $59 \%$ by using 20 equivalents of $\mathrm{AcOH}$ in toluene at $90{ }^{\circ} \mathrm{C}$. Altogether, these results not only highlight the efficiency of the optimized paired electrochemical protocol but also demonstrate its scalability. ${ }^{26}$

\section{SUMMARY}

The key mechanistic features of the developed conditions are summarized in Scheme 6. To increase the practicality of the Mn-mediated $\alpha$-radical addition of carbonyls to olefins, the goal of this study was to lower the amount of carbonyl starting material to 3 equivalents. Fixing this parameter impacted the first step of the mechanism where the carbonyl moiety needs to coordinate the Mn-catalyst. Therefore, increasing the concentration (from $0.1 \mathrm{M}$ to $0.75 \mathrm{M}$ ) was crucial to obtain the desired product in good yield (Scheme 6, panel A). The following loss of proton is afforded through an intramolecular deprotonation process where the presence of the acetate ligands proved essential. Indeed, external bases or additives were detrimental for the reaction to occur with high efficiency (Scheme 6, panel B). The oxidation of the resulting enolate has been extensively studied in the literature and none of the reaction parameters we have investigated improved it (Scheme 6, panel C). Conversely, for the free radical addition step, our study systematically highlighted the importance of the alkene geometry and substitution (Scheme 6, panel D). The high concentration also favored this step of the mechanism. The use of EtOH instead of $\mathrm{AcOH}$, in addition to increasing the functional group tolerance, positively impacted the final HAT step (Scheme 6, panel E). Finally, the use of electrochemical conditions to reoxidize Mn(II) to Mn(III) allowed the development of a robust and general catalytic set of conditions where a precisely controlled $[\mathrm{Mn}] /[\mathrm{AcOH}]$ ratio was found to be critical (Scheme 6, panel E).

\section{CONCLUSION}

An in-depth study of the Mn-mediated $\alpha$-radical addition of carbonyls to addition to olefins has been assembled allowing the development of a new and general set of reaction conditions. A wide range of functional groups including ester, cyano, nitro, free and TBS protected alcohols, and acetyl groups were tolerated, and several carbonyls and olefins proved competent coupling partners. Understanding the effect of solvent, concentration, temperature, amount of catalyst as well as the impact of additives has enabled us to identify a list of eight key experiments that can quickly be executed to optimize challenging reactions. This approach was successfully applied to four different initially low yielding substrates, proved highly efficient, and led to the creation of 


\section{Scheme 6. Key mechanistic features of the developed conditions.}

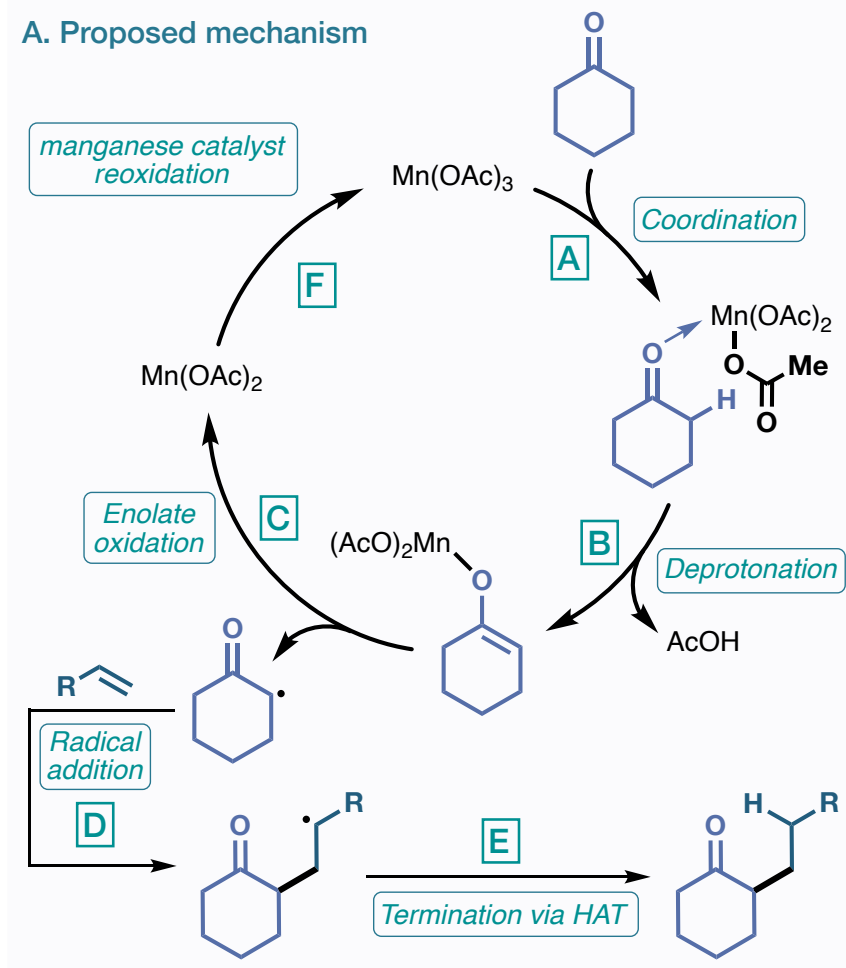

a predictive model based on the pKa of the carbonyl compound and both the substitution and geometry of the alkene coupling partner. Finally, development of a robust and practical electrocatalytic version of the reaction enabled the departure from stoichiometric manganese loadings. The eprocedure requires only 3 equivalents of carbonyl starting material to achieve good conversions, uses two inexpensive graphite electrodes and a safe electrolyte. Importantly, this paired electrochemical process does not require the use of an undivided cell and was straightforwardly scaled-up to 6 $\mathrm{mmol}$ in a single $20 \mathrm{~mL}$ vial. Overall, both stoichiometric and electrocatalytic protocols should find applications in academic and industrial environments and will enable the development of new Mn-based catalytic systems.

\section{ASSOCIATED CONTENT}

\section{Supporting Information}

The Supporting Information is available free of charge on the ACS Publications website.

The Supporting Information contains experimental procedures and graphical abstracts for both the stoichiometric and catalytic reactions, investigation of the reaction parameters, optimization of the reaction conditions (stoichiometric and catalytic), the optimization of low yielding substrates, analysis, and compound characterization data.

\section{AUTHOR INFORMATION}

\section{Corresponding Author}

*Julien C. Vantourout: julien.vantourout@univ-lyon1.fr ORCID: 0000-0002-0602-069X

\section{B. Key features of the developed conditions}

A As the amount of carbonyl (3 equiv) was lowered compared to reported conditions, concentration $(0.75 \mathrm{M})$ and amount of catalyst (1.5 equiv) were crucial parameters to optimize.

B pKa of the carbonyl proved important (Scheme 4C.1). The deprotonation occurs via an intramolecular mechanism and therefore the nature of the ligand (acetate) on the manganese catalyst is important. External bases did not afford any improvement and proved detrimental for the reaction outcome. $\mathrm{Mn}$ (III) is able to oxidize the enolate affording the formation of the alpha-keto radical and $\mathrm{Mn}(\mathrm{II})$. Alkene substitution and geometry are essential and afford different reaction outcomes. Concentration $(0.75 \mathrm{M})$ was also an important parameter to optimize to favor this step.

E The HAT step is important as it delivers the desired product. EtOH or toluene proved optimal.

Regeneration of the Mn(III) active catalyst was not possible under argon atmosphere and chemical oxidants increased the amount of by-products. Electrochemical conditions using a controled amount of $\mathrm{AcOH}$ (optimum ratio $\mathrm{Mn} / \mathrm{AcOH}$ ) enabled the development of robust and easily scalable catalytic conditions.

\section{Authors}

Sylvain Charvet - ORCID: 0000-0003-1612-9338

Maurice Médebielle - ORCID: 0000-0002-6032-4790

\section{Author Contributions}

The manuscript was written through contributions of all authors. All authors have given approval to the final version of the manuscript.

\section{ACKNOWLEDGMENT}

This work was supported by the CNRS, the French Ministry of Research, the ICBMS and the Université Claude Bernard Lyon 1. The NMR and Mass Centres of the Université Claude Bernard Lyon 1 are thanked for their contribution. We thank J. Merad, A. Amgoune, A. Tlili, G. Tran, E. Metay, F. Popowycz, K. S. McClymont, S. Gnaim and P. S. Baran for insightful discussions.

\section{REFERENCES}

(1) For a selection of book chapters and reviews: (a) Horváth, I. T. Introduction: Sustainable Chemistry. Chem. Rev. 2018, 118, 369-371. (b) Zuin, V. G.; Eilks, I.; Elschami, M.; Kümmerer, K. Education in Green Chemistry and in Sustainable Chemistry: Perspectives Towards Sustainability. Green Chem. 2021, 23, 1594-1608. (c) Nikolopoulou, A.; Ierapetritou, M. G. Optimal Design of Sustainable Chemical Processes and Supply Chains: A Review. Comput. Chem. Eng. 2012, 44, 94-103. (d) Ranke, J.; Stolte, S.; Störmann, R.; Arning, J.; Jastorff, B. Design of Sustainable Chemical Products: The Example of Ionic Liquids. Chem. Rev. 2007, 107, 2183-2206. (e) Clarke, C. J.; Tu, W.-C.; Levers, O.; Bröhl, A.; Hallett, J. P. Green and Sustainable Solvents in Chemical Processes. Chem. Rev. 2018, 118, 747-800.

(2) For a selection of reviews: (a) Alig, L.; Fritz, M.; Schneider, S. First-Row Transition Metal (De)Hydrogenation Catalysis Based on Functional Pincer Ligands. Chem. Rev. 2019, 119, 2681-2751. (b) Taylor, L. J.; Kays, D. L. Low-Coordinate FirstRow Transition Metal Complexes in Catalysis and Small 
Molecule Activation. Dalton Trans. 2019, 48, 12365-12381. (c) Peng, J.-B.; Wu, F.-P.; Wu, X.-F. First-Row Transition-MetalCatalyzed Carbonylative Transformations of Carbon Electrophiles. Chem. Rev. 2019, 119, 2090-2127. (d) Van der Vlugt, J. I. Cooperative Catalysis with First-Row Late Transition Metals. Eur. J. Inorg. Chem. 2012, 2012, 363-375. (e) Miao, J.; Ge, H. Recent Advances in First-Row-Transition-Metal-Catalyzed Dehydrogenative Coupling of $\mathrm{C}\left(\mathrm{Sp}^{3}\right)-\mathrm{H}$ Bonds: Metal-Catalyzed Dehydrogenative Coupling of $\mathrm{C}\left(\mathrm{Sp}^{3}\right)-\mathrm{H}$ Bonds. Eur. J. Org. Chem. 2015, 7859-7868.

(3) For a selection of book chapters and reviews: (a) Carney, J. R.; Dillon, Barry. R.; Thomas, S. P. Recent Advances of Manganese Catalysis for Organic Synthesis. Eur. J. Org. Chem. 2016, 39123929. (b) Kallmeier, F.; Kempe, R. Manganese Complexes for (De)Hydrogenation Catalysis: A Comparison to Cobalt and Iron Catalysts. Angew. Chem. Int. Ed. 2018, 57, 46-60. (c) Aneeja, T.; Neetha, M.; Afsina, C. M. A.; Anilkumar, G. Recent Advances and Perspectives in Manganese-Catalyzed C-H Activation. Catal. Sci. Technol. 2021, 11, 444-458. (d) Huang, X.; Bergsten, T. M.; Groves, J. T. Manganese-Catalyzed Late-Stage Aliphatic C-H Azidation. J. Am. Chem. Soc. 2015, 137, 53005303. (e) Hu, Y.; Zhou, B.; Wang, C. Inert C-H Bond Transformations Enabled by Organometallic Manganese Catalysis. Acc. Chem. Res. 2018, 51, 816-827. (f) Borghs, J. C.; Tran, M. A.; Sklyaruk, J.; Rueping, M.; El-Sepelgy, O. Sustainable Alkylation of Nitriles with Alcohols by Manganese Catalysis. J. Org. Chem. 2019, 84, 7927-7935. (g) Trovitch, R. J. The Emergence of Manganese-Based Carbonyl Hydrosilylation Catalysts. Acc. Chem. Res. 2017, 50, 2842-2852. (h) Mukherjee, A.; Milstein, D. Homogeneous Catalysis by Cobalt and Manganese Pincer Complexes. ACS Catal. 2018, 8, 11435-11469. (i) Cahiez, G.; Duplais, C.; Buendia J. Chemistry of Organomanganese(II) Compounds. Chem. Rev. 2009, 109, 1434-1476.

(4) For a selection of book chapters and reviews: (a) Lamoureux, G.; Agüero, C. A Comparison of Several Modern Alkylating Agents. Arkivoc 2009, 1, 251-264. (b) Caine, D. In Comprehensive Organic Chemistry; Trost, B. M., Fleming, I., Pattenden, G., Eds.; Pergamon: Oxford, U.K., 1991; Vol. 3, pp 1-63. (c) Reetz, M. T. Lewis Acid Induced $\alpha$-Alkylation of Carbonyl Compounds. Angew. Chem. Int. Ed. Engl. 1982, 21, 96-108. (d) Carey, F. A.; Sundberg, R. J. Part B: Reactions and Synthesis; Springer Berlin Heidelberg: Berlin, Heidelberg, 2001. (e) Modern Carbonyl Chemistry; Junzo, O., Eds.; Wiley-VCH Weinheim, 2000. (e) Organic Chemistry; Clayden, J., Greeves, N., Warren, S., Wothers, P., Eds.; Oxford University Press: Oxford, 2001.

(5) For a selection of total synthesis and methodology papers: (a) Smith, B. T.; Wendt, J. A.; Aube, J. First Asymmetric Total Synthesis of (+)-Sparteine. Org. Lett. 2002, 4, 2577-2579. (b) Ataraschi, S.; Choi, J-K.; Ha, D-C.; Hart, D.J.; Kuzmich, D.; Lee, C-S.; Ramesh, S.; Wu, S. C. Free Radical Cyclizations in Alkaloid Total Synthesis: ( \pm )-21-Oxogelsemine and ( \pm )-Gelsemine. J. Am. Chem. Soc. 1997, 119, 6226-6241. (c) Taber, D. F.; Neubert, T. B.; Rheingold, A. L. Synthesis of (-)-Morphine. J. Am. Chem. Soc. 2002, 124, 12416-12417. (d) Shneider, O. S.; Pisarevsky, E.; Fristrup, P.; Szpilman, A. M. Oxidative Umpolung $\alpha$-Alkylation of Ketones. Org. Lett. 2015, 17, 282-285. (e) Tomioka, K.; Ando, K.; Takemasa, Y.; Koga, K. Asymmetric Alkylation of $\alpha$ Alkyl $\beta$-Keto Esters. J. Am. Chem. Soc. 1984, 106, 2718-2719.

(6) For a selection of papers: (a) Nakamura, M.; Hatakeyama, T.; Nakamura, E. $\alpha$-Alkylation of Ketones by Addition of Zinc Enamides to Unactivated Olefins. J. Am. Chem. Soc. 2004, 126, 11820-11825. (b) Mo, F.; Dong, G. C-H bond activation. Regioselective ketone $\alpha$-alkylation with simple olefins via dual activation. Science 2014, 345, 68-72. (c) Dang, Y.; Qu, S.; Tao, Y.; Deng, X.; Wang, Z.-X. Mechanistic Insight into Ketone $\alpha$-Alkylation with Unactivated Olefins via $\mathrm{C}-\mathrm{H}$ Activation Promoted by Metal-Organic Cooperative Catalysis (MOCC): Enriching the MOCC Chemistry. J. Am. Chem. Soc. 2015, 137, 6279-6291. (d) Huang, Z.; Lim, H. N.; Mo, F.; Young, M. C.; Dong, G.
Transition Metal-Catalyzed Ketone-Directed or Mediated C-H Functionalization. Chem. Soc. Rev. 2015, 44, 7764-7786. (e) Xing, D.; Dong, G. Branched-Selective Intermolecular Ketone $\alpha$-Alkylation with Unactivated Alkenes via an Enamide Directing Strategy. J. Am. Chem. Soc. 2017, 139, 13664-13667. (f) Li, X.; Wu, H.; Lang, Y.; Huang, G. Mechanism, Selectivity, and Reactivity of Iridium- and Rhodium-Catalyzed Intermolecular Ketone $\alpha$-Alkylation with UnActivated Olefins via an Enamide Directing Strategy. Catal. Sci. Technol. 2018, 8, 2417-2426. (g) Xing, D.; Qi, X.; Marchant, D.; Liu, P.; Dong, G. Branched-Selective Direct $\alpha$-Alkylation of Cyclic Ketones with Simple Alkenes. Angew. Chem. Int. Ed. 2019, 58, 4366-4370. (h) Lim, H. N.; Xing, D.; Dong, G. Transition-Metal-Catalyzed Ketone $\alpha$-Alkylation and Alkenylation with Simple Alkenes and Alkynes Through a Dual Activation Strategy. Synlett 2019, 30, 674684. (i) Mo, F.; Dong, G. Regioselective Ketone $\alpha$-Alkylation with Simple Olefins via Dual Activation. Science 2014, 345, 68-72. (j) Iuchi, Y.; Obora, Y.; Ishii, Y. Iridium-Catalyzed $\alpha$-Alkylation of Acetates with Primary Alcohols and Diols. J. Am. Chem. Soc. 2010, 132, 2536-2537. (k) Piehl, P.; Amuso, R.; Alberico, E.; Junge, H.; Gabriele, B.; Neumann, H.; Beller, M. Cyclometalated Ruthenium Pincer Complexes as Catalysts for the $\alpha$-Alkylation of Ketones with Alcohols Chem. Eur. J. 2020, 26, 6050-6055.

(7) Bush, J. B.; Finkbeiner, H. Oxidation Reactions of Manganese(III) Acetate. Formation of Gamma-Lactones from Olefins and Acetic Acid. J. Am. Chem. Soc. 1968, 90, 5903-5905.

(8) Heiba, E. I.; Dessau, R. M.; Koehl, W. J. Oxidation by Metal Salts. IV. A New Method for the Preparation of $\gamma$-Lactones by the Reaction of Manganic Acetate with Olefins. J. Am. Chem. Soc. 1968, 90, 5905-5906.

(9) Vinogradov, M. G.; Verenchikov, S. P.; Nikishin, G. I. Preparation of Acetonyl Radicals in the Oxidation of Acetone with Manganese Triacetate. Russ. Chem. Bull. 1971, 20, 189-189.

(10) (a) Snider, B. B. Manganese(III)-Based Oxidative Free-Radical Cyclizations. Chem. Rev. 1996, 96, 339-364. (b) Iqbal, J.; Bhatia, B.; Nayyar, N. K. Transition Metal-Promoted Free-Radical Reactions in Organic Synthesis: The Formation of CarbonCarbon Bonds. Chem. Rev. 1994, 94, 519-564. (c) Badanyan, S.O.; Melikyan, G.G.; Mkrtchyan, D. A. The Introduction of Functional Groups Into Unsaturated Systems by Carbonyl Compounds in the Presence of Manganese(III) Acetate. Russ. Chem. Rev. 1989, 58, 286-296. (d) Snider, B. B. Manganese(III) Acetate-Mediated Cyclizations. In Manganese Catalysis in Organic Synthesis; John Wiley \& Sons, Ltd, 2021; pp 293-322. (e) Snider, B. B. Manganese(III)-Mediated Radical Reactions. In Radicals in Organic Synthesis; Renaud, P., Sibi, M. P., Eds.; Wiley-VCH Verlag GmbH: Weinheim, Germany, 2001; pp 198-218. (f) Davies, D. T.; Kapur, N.; Parsons, A. F. Preparation of N-Heterocycles by Radical Cyclisation of Enamides Mediated by Manganese(III) or Copper(I). A Comparison of Cyclisation Methods. Tetrahedron 2000, 56, 3941-3949. (g) Mondal, M.; Bora, U. Recent Advances in Manganese(III) Acetate Mediated Organic Synthesis. RSC Adv. 2013, 3, 18716-18754. (h) Sanz-Navarro, S.; Garnes-Portolés, F.; López-Cruz, C.; EspinósFerri, E.; Corma, A.; Leyva-Pérez, A. Radical $\alpha$-Alkylation of Ketones with Unactivated Alkenes Under Catalytic and Sustainable Industrial Conditions. Appl. Catal. 2021, 613, 118021-118028.

(11) Fristad, W. E.; Peterson, J. R.; Ernst, A. B.; Urbi, G. B. Mechanisms for Manganese(III) Oxidations with Alkenes. Tetrahedron 1986, 42, 3429-3442.

(12) Snider, B. B. Mechanisms of Mn(OAc)3-Based Oxidative FreeRadical Additions and Cyclizations. Tetrahedron 2009, 65, 10735-10744.

(13) (a)Melikyan, G. G.; Mkrtchyan, D. A.; Lebedeva, K. V.; Myaéorg, U. Yu.; Panosyan, G. A.; Badanyan, Sh. O. Synthesis of ( \pm )-Cisetradec-5-En-4-Olide the Racemate of the Sex Pheromone of the Japanese Beetle. Chem. Nat. Compd. 1984, 20, 94-98. (b) Yang, F. Z.; Trost, M. K.; Fristad, W. E. Simple Route to 
Substituted Tetralones. Tetrahedron Lett. 1987, 28, 14931496. (c) Gardrat, C. A Synthesis of Norbisabolide via a Synthon Prepared by a Free Radical Reaction. Synthetic Communications 1984, 14, 1191-1192. (d) White, J. D.; Somers, T. C.; Yager, K. M. Synthesis of Dihydropallescensin D via Manganese(III) Mediated Cyclization of an Olefinic $\beta$-Keto Ester. Tetrahedron Lett. 1990, 31, 59-62. (e) Corey, E. J.; Wu, Y. J. Total Synthesis of $( \pm)$-Paeoniflorigenin and Paeoniflorin. J. Am. Chem. Soc. 1993, 115, 8871-8872. (f) Paquette, L. A.; Schaefer, A. G.; Springer, J. P. Synthesis of ( \pm )-14-Epiupal by Manganese(III) $\gamma$-Lactone Annulation. Tetrahedron 1987, 43, 55675582.

(14) (a) Snider, B. B.; Mohan, R. M.; Kates, S. A. Manganese(III)Based Oxidative Free-Radical Cyclization. Synthesis of $( \pm)$-Podocarpic Acid J. Org. Chem. 1985, 50, 3659-3661. (b) Zoretic, P. A.; Ramchandani, M.; Caspar, M. L. Aspects of Manganese (III)-Promoted Oxidative Free Radical Cyclizations to Functionalized Bicyclic Systems. Synth. Commun. 1991, 21, 915922. (c) Pettus, T. R. R.; Chen, X.-T.; Danishefsky, S. J. A Fully Synthetic Route to the Neurotrophic Illicinones by Sequential Aromatic Claisen Rearrangements J. Am. Chem. Soc. 1998, 120, 12684-12685. (d) Trotta, A. H. Total Synthesis of Oridamycins A and B Org. Lett. 2015, 17, 3358-3361. (e) Merchant, R. R.; Oberg, K. M.; Lin, Y.; Novak, A. J. E.; Felding, J.; Baran, P. S. Divergent Synthesis of Pyrone Diterpenes via Radical Cross Coupling. J. Am. Chem. Soc. 2018, 140, 7462-7465. (f) Corey, E. J.; Kang, M. C. A New and General Synthesis of Polycyclic Gamma-Lactones by Double Annulation. J. Am. Chem. Soc. 1984, 106, 5384-5385.

(15) (a) Ho, T.-L.; Po-Fei Yang. Synthesis of Phenolic Sesquiterpenes via Oxidative Cleavage of Benzocycloalkenols. Tetrahedron 1995, 51, 181-192. (b) Trivedi, S. V.; Mamdapur, V. R. Indian J. Chem. 1986, 25, 1160.

(16) (a) Qian, C. Y.; Nishino, H.; Kurosawa, K.; Korp, J. D. Manganese(II) Acetate-Mediated Double 2-Hydroperoxyalkylations of Barbituric Acid and Its Derivatives. J. Org. Chem. 1993, 58, 4448-4451. (b) Qian, C. Y.; Yamada, T.; Nishino, H.; Kurosawa, K. Manganese (II and III)-Mediated Synthesis of Cyclic Peroxides from Alkenes, Active Methylene Compounds, and Molecular Oxygen. Bull. Chem. Soc. Jpn. 1992, 65, 1371-1378.

(17) Kagayama, T.; Fuke, T.; Sakaguchi, S.; Ishii, Y. A Remarkable Effect of Bases on the Catalytic Radical Addition of Cyanoacetates to Alkenes Using a Mn(II) $/ \mathrm{Co}(\mathrm{II}) / \mathrm{O}_{2}$ Redox System. Bull. Chem. Soc. Jpn. 2005, 78, 1673-1676.

(18) Shundo, R.; Nishiguchi, I.; Matsubara, Y.; Hirashima, T. Selective Coupling of Non-Activated Olefins with Ethyl Cyanoacetate by $\mathrm{Mn}^{3+}-$ Mediated Anodic Oxidation. Chem. Lett. 1990, 19, 2285-2288.

(19) While the intramolecular version of the reaction has been extensively studied (see references 10 to 14) and applied in total synthesis, the intramolecular version has only been developed for specific substrates with no general set of conditions reported to date. This observation has been reported in several book chapters and reviews.
(20) (a) Snider, B. B.; Meritt, J. E.; Dombroski, M. A.; Buckman, B. O. Solvent Effects on Manganese(III)-Based Oxidative Free-Radical Cyclizations: Ethanol and Acetic Acid. J. Org. Chem. 1991, 56, 5544-5553. (b) Okano, M. The Participation of Solvents in the Reaction of Alkenes with Manganese(III) Acetate. Bull. Chem. Soc. Jpn. 1976, 49, 1041-1046. (c) Snider, B. B.; McCarthy, B. A. Ligand, Solvent, and Deuterium Isotope Effects in Mn(III)-Based Oxidative Free-Radical Cyclizations. J. Org. Chem. 1993, 58, 6217-6223.

(21) (a) Magnus, P.; Payne, A. H.; Waring, M. J.; Scott, D. A.; Lynch, V. Conversion of $\alpha, \beta$-Unsaturated Ketones Into $\alpha$-Hydroxy Ketones Using an Mn(III) Catalyst, Phenylsilane and Dioxygen: Acceleration of Conjugate Hydride Reduction by Dioxygen. Tetrahedron Lett. 2000, 41, 9725-9730. (b) Shevick, S. L.; Wilson, C. V.; Kotesova, S.; Kim, D.; Holland, P. L.; Shenvi, R. A. Catalytic Hydrogen Atom Transfer to Alkenes: a Roadmap for Metal Hydrides and Radicals. Chem. Sci. 2020, 11, 12401-12422.

(22) Collins, K. D.; Glorius, F. A Robustness Screen for the Rapid Assessment of Chemical Reactions. Nat. Chem. 2013, 5, 597-601.

(23) (a) Corey, E. J.; Gross, A. W. Carbolactonization of Olefins Under Mild Conditions by Cyanoacetic and Malonic Acids Promoted by Manganese(III) Acetate. Tetrahedron Lett. 1985, 26, 4291-4294. (b) Nedelec, J.-Y.; Lachaise, I.; Nohair, K.; Paugam, J. P.; Hakiki, M. Mn(III)-Mediated In-Cell Electrochemical Addition of Active Methylene Compounds to Olefins: Synthetic and Mechanistic Aspects. Bull. Soc. Chim. Fr. 1995, 132, 843849.

(24) (a) Nikishin, G. I.; Vinogradov, M. G.; Il'ina, G. J. Org. Chem. USSR 1972, 8, 1422. (b) Nikishin, G. I. Homolytic Reactions of Functional Oxygen-Containing Compounds Initiated by Compounds of Variable Valency Metals. Russ. Chem. Bull. 1984, 33, 109-119. (c) Vinogradov, M. G.; Dolinko, V. I.; Nikishin, G. I. Oxidative Addition of Chloromalonic Ester to Unsaturated Compounds under the $\mathrm{Mn}(\mathrm{OAc})_{3}-\mathrm{LiCl}$ System. Russ. Chem. Bull. 1984, 33, 1884-1887. (d) Ito, N.; Nishino, H.; Kurosawa, K. The reaction of Olefins with Malonic Acid in the Presence of Manganese(III) Acetate. Bull. Chem.Jpn. 1983, 56, 3527-3528. (e)Fristad, W. E.; Hershberger, S. S. Manganese(III)-Mediated Spirodilactonization. J. Org. Chem. 1985, 50, 1026-1031.

(25) (a) Warsinsky, R.; Steckhan, E. Oxidative Free-Radical Additions of $\alpha$-Nitro Ketones and $\alpha$-Nitro Amides to Alkenes and Alkynes Mediated by Electrochemically Regenerable Manganese(III) Acetate. J. Chem. Soc., Perkin Trans. 1 1994, 14, 2027 2037. (b) Snider, B. B.; McCarthy, B. A. Mn(III)-Mediated Electrochemical Oxidative Free-Radical Cyclizations, ACS Symposium Series 1994, 7, 84-97.

(26) Vantourout, J. C. From Bench to Plant: An Opportunity for Transition Metal Paired Electrocatalysis. Org. Process Res. Dev. 2021, DOI: 10.1021/acs.oprd.1c00046. 


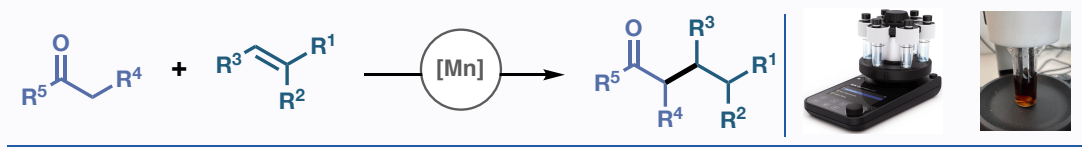

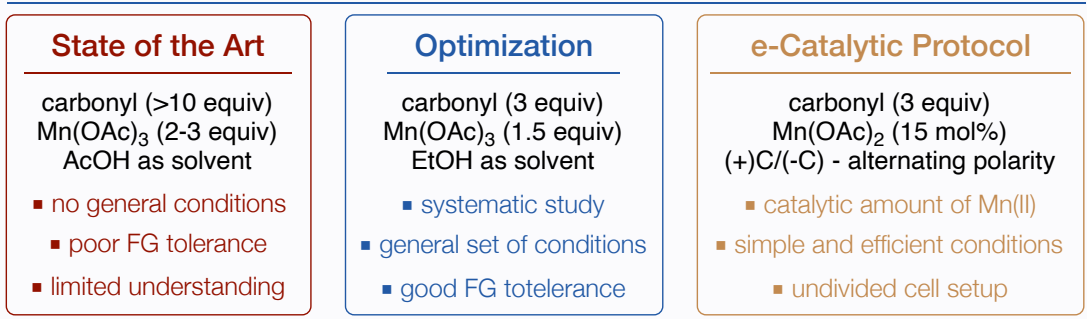

